\title{
Scaling Milton Keynes Power Requirements for Electrical Transportation
}

\author{
Jesus Nieto-Martin ${ }^{1}$, Eugene Butans ${ }^{2}$ \\ ${ }^{1}$ Power and Propulsion Sciences Group \\ ${ }^{2}$ Integrated Vehicle Health Management Centre \\ Cranfield University \\ Cranfield, United Kingdom \\ j.nietomartin@cranfield.ac.uk
}

\author{
Pablo Correa-Castillo, Jerome Fontaine, Alexis \\ Gonnelle, Mohamed Lahjibi, Carlos Vrancken \\ Power Engineering Centre \\ Cranfield University \\ Cranfield, United Kingdom
}

\begin{abstract}
Milton Keynes is home to the UK's first installation of a wirelessly charged passenger bus route. This Inductive Power Transfer (IPT) system enables a fleet of 8 electric buses to service a demanding 15-mile urban route. Opportunistic wireless charging of the batteries during the layover time at the routes allows reducing the size of the batteries, consequently improving cost and performance characteristics of the bus. This paper aims to analyze the effects of electric buses on the electricity distribution grid. In particular, the paper analyses scalability of the IPT solution to all urban routes in Milton Keynes and compares peak power requirements generated at different points in the network with typical industrial and commercial (I\&C) loads.
\end{abstract}

Index Terms - Capacity Planning, Demand forecasting, Transportation, Technology planning.

\section{INTRODUCTION}

The United Kingdom is committed to significantly reduce its emissions of greenhouse gases up to $80 \%$ by 2050 , compared to 1990 levels. Milton Keynes (MK) council estimates $27 \%$ savings in $\mathrm{CO}_{2}$ by 2020 and $100 \%$ of $\mathrm{CO}_{2}$ emissions by 2050 [1]. MK is the first city in the UK which has committed to hosting an innovative installation featuring a wirelessly charged all-Electric Bus (EB) route. Thus, considering the objective, intermediate milestones were identified which would allow the city of Milton Keynes to cope with these environmental targets.

TABLE I. ELECTRIFICATION SCENARIOS AND \% OF CO2 SAVINGS

\begin{tabular}{|l|l|l|l|l|}
\hline Scenario & $\mathbf{2 0 2 0}$ & $\mathbf{2 0 3 0}$ & $\mathbf{2 0 4 0}$ & $\mathbf{2 0 5 0}$ \\
\hline Goal \% $\mathrm{CO}_{2}$ savings & 27 & 51 & 76 & 100 \\
\hline
\end{tabular}

Currently the city runs a trial using the Inductive Power Transfer (IPT) system, which enables a fleet of 8 buses to service a demanding 15-mile urban route linking Bletchley to Wolverton via the city centre (route 7) [2].

Western Power Distribution Innovation

Avonbank, Feeder Road, Bristol BS2 0TB
Due to their high power requirements, electric buses usually rely on heavy batteries to complete long and frequent journeys. The trial in MK is different, in the sense that the buses take advantage of two opportunistic charging windows at the starting and ending points of the route, and that allows the size of the battery to be reduced. Combined with an overnight plug-in charging at the depot, the bus maintains its state of charge at any moment above the $30 \%$ safety battery limit.

In the course of the trial approximately 500 tonnes of $\mathrm{CO}_{2}$ are saved each year on route 7 [3]. Notwithstanding the significant reduction of emissions, the IPT charging pattern is raising some concerns of the ability of the electricity distribution network to cope up with these intermittent inductive loads. From the Distribution Network Operator (DNO) view, this intermittent demand presents a major challenge for asset management planning.

\section{A. Bus Route Electrification Constraints}

A typical commercial bus route has a timetable, with route start and end points, where the vehicles usually stop for scheduled lengths of time. Recharging the batteries during these periods is known as "opportunistic charging".

The EBs require a significant upfront investment, in particular related to the cost of the battery and the singular design of the vehicle [4]. According to Pihlatie et al., the purchase price of a long range electric bus is $40 \%$ higher than a comparable conventional diesel bus [5].

The battery is the core limitation. The longer the route, the heavier the battery, and the more expensive it will be [6] Hence, the battery size selection will determine the amount of money which will be needed and directly impact the economics of any coming further bus electrification. Currently, Li-ion batteries are the most efficient and advanced ones offering the best outcomes but they are also the least affordable [6]. IPT technologies allow reducing the size of the batteries which ends up with lower CAPEX compared with exclusive plug-in electric buses [6]. 


\section{B. IPT for Electrical Buses}

There are several examples of trials with IPT for buses around the world displayed in [7]. It can be observed that MK scheme presents the most demanding characteristics in terms of bus size and distance without charging. Route 7 in MK covers longer distances and its buses are significantly larger, as displayed on Table 2. This results in a higher battery capacity and more powerful charging points.

TABLE II. IPT BUSES PROJECTS ACROSS THE WORLD

\begin{tabular}{|c|c|c|c|c|c|c|c|c|}
\hline & & Buses & $\begin{array}{l}\text { Passenger } \\
\text { Capacity }\end{array}$ & \begin{tabular}{|c|} 
Daily \\
distance
\end{tabular} & $\begin{array}{l}\text { Energy } \\
\text { storage }\end{array}$ & $\begin{array}{l}\text { Charge } \\
\text { points }\end{array}$ & $\begin{array}{c}\text { Distance } \\
\text { to charge } \\
\text { points }\end{array}$ & $\begin{array}{c}\text { Charging } \\
\text { Power }\end{array}$ \\
\hline \multirow{4}{*}{ 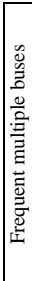 } & $\begin{array}{l}\text { Genoa } \\
(2002)\end{array}$ & 8 & $\begin{array}{c}15 \text { seats }+ \\
22 \text { standing }\end{array}$ & N/A & $\begin{array}{c}\text { Lead-Gel } \\
63 \mathrm{kWh}\end{array}$ & 1 & $5,000 \mathrm{~m}$ & $60 \mathrm{~kW}$ \\
\hline & $\begin{array}{l}\text { Turin } \\
(2003)\end{array}$ & \begin{tabular}{|c|}
23 \\
2 lines \\
\end{tabular} & $\begin{array}{c}15 \text { seats }+ \\
22 \text { standing }\end{array}$ & $200 \mathrm{~km}$ & $\begin{array}{c}\text { Lead-Gel } \\
63 \mathrm{kWh}\end{array}$ & $\begin{array}{c}4 \\
\text { per line } \\
\end{array}$ & $\begin{array}{r}6,273 \mathrm{~m} \\
5,243 \mathrm{~m} \\
\end{array}$ & $60 \mathrm{~kW}$ \\
\hline & $\begin{array}{l}\text { Utrecht } \\
(2010)\end{array}$ & 3 & $\begin{array}{c}15 \text { seats }+ \\
22 \text { standing }\end{array}$ & $150 \mathrm{~km}$ & $\begin{array}{c}\text { Lead-Gel } \\
63 \mathrm{kWh}\end{array}$ & 1 & $4,800 \mathrm{~m}$ & $60 \mathrm{~kW}$ \\
\hline & $\begin{array}{c}\text { Milton } \\
\text { Keynes (2014) }\end{array}$ & 8 & $\begin{array}{l}37 \text { seats }+ \\
9 \text { standing }\end{array}$ & $252 \mathrm{~km}$ & $\begin{array}{c}\text { Li-ion } \\
150 \mathrm{kWh}\end{array}$ & 2 & $24,000 \mathrm{~m}$ & $120 \mathrm{~kW}$ \\
\hline
\end{tabular}

One of the main IPT challenges is to charge the battery during the day without affecting the bus schedule. There is a variable window between journeys of 5-10 min that can be used to top up the battery in addition to the overnight charging. With the installation of an IPT charger at each route end, the battery requirement has been successfully lowered to $150 \mathrm{kWh}$ of useful capacity [8]. Without the IPT charging, the bus can continuously operate for approx. 8 hours, whereas with multiple IPT charging periods would work up to 18 hours [9].

\section{Effects on the grid}

Scaling up EB fleet is likely to produce impacts on the headroom and power quality $[10,11]$ of the distribution network to sustain and operate peaks of intermittent loads. For EBs to be implemented at a large scale, the resilience and reliability of the grid to an additional and uncontrolled demand causing stress to the grid have to be assessed [6]. Specifically, the most contributing factors are the number of vehicles, charging time and network infrastructure, with the present study focussing on the former two [10].

\section{METHODOLOGY}

This section describes the methodology for modelling the performance of EB based on Western Power Distribution (WPD) data of the current route 7, investigating the scalability of this system to other urban bus routes, proposing future uptake scenarios.

The data collection process has been developed, providing the basic input data to the model and the information about the other bus routes necessary to analyse its scalability. Then, the model of the existing trial was generated adapting from [13] a complete modelling cycle, from understanding the environment through design, verification, validation, and analysis. The different operational characteristics of the other routes, currently run by diesel buses, required an adaptation to the IPT charging scheme, which is also described. Finally, to propose future uptake scenarios, a Multi-Criteria Decision
Analysis (MCDA) [14] was developed including all the variables that influence the bus route electrification roadmap.

\section{A. Data modelling}

Once the conceptual models had been completed, the different modules were implemented using the numerical computational package Scilab [15] and spreadsheets for input data. Figure 1 highlights the overall simulation model, its different modules and illustrates the overall data flows in the Scilab implementation.

Thus, the model uses the buses timetables coupled with route information such as length and distances between stops, to calculate power requirements for each buses. The state of charge is then calculated based on the charger characteristics. Once all bus charging calculations have been compiled, the electricity demand at any given time for any of the charging points can be estimated. Providing that each module has been verified, validation process can then be run with historical data provided by WPD.

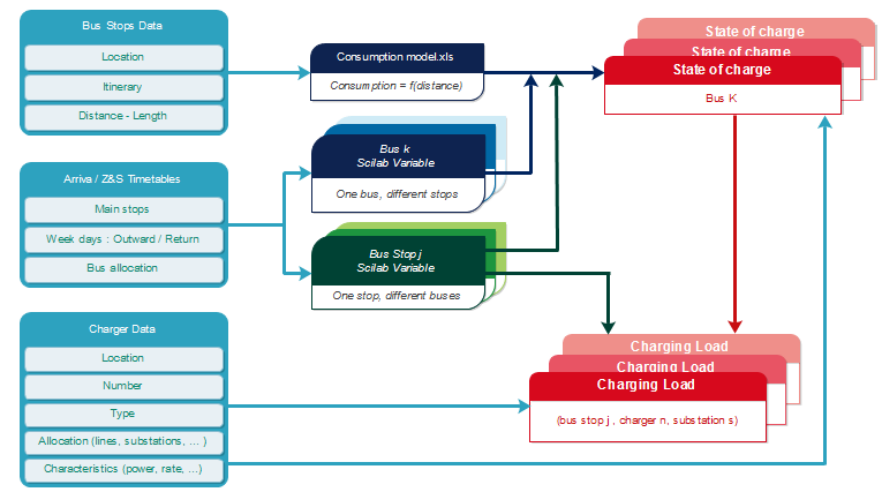

Figure 1. Simplified diagram of Scilab data flows

\section{B. Energy consumption model}

For the purposes of this project, the energy consumption (1), will be assumed to be dependent on the distance $(d)$ between the bus stops, with shorter distances reducing efficiency and increasing energy consumption. A $4^{\text {th }}$ degree polynomial regression model was applied to fit the values obtained by [16]. Results were obtained using optimised speed profiles, which were found to be $12 \%$ lower than current measured energy consumption. So for our model, a speed correction factor $(s)$ was applied. A powertrain factor $(p)$ was applied to adjust for the fact that the energy consumption is affected by the bus configuration and design, as described in [17], a poorly designed powertrain configuration can increase the energy consumption of an electric bus up to $20 \%$. For our model, an average value of $10 \%$ increase in consumption was assumed to describe a typical powertrain configuration, the average value between the best and the worst configuration.

$$
E_{t, \text { speed,powertrain }}= \begin{cases}\frac{p s d}{1000} \times E, & 0<d<894 \\ \frac{p s d}{1000} \times E_{\text {avg }} & d \geq 894\end{cases}
$$

where $d$ is the distance between stops for a particular segment, expressed in metres, $s$ is the speed profile correction factor, value used is $1.12, p$ is the powertrain correction 
factor, value used is $1.1, E$ is the energy consumption per distance, expressed in $\mathrm{kWh} / \mathrm{km}, E_{t, \text { speed,powertrain }}$ is the energy consumption for a segment of length $d$, expressed in $\mathrm{kWh}$, adjusted for speed profile and powertrain design. The original model by [16] only covered distances up to 894 metres between stops. For longer distances, a constant number was assumed, $E_{\text {avg }}$, being the value used $0.93 \mathrm{kWh} / \mathrm{km}$.

\section{Battery State- of-Charge (SoC) model}

This model generates the battery energy level at each minute of an entire day from 00:00 to 23:59. The Scilab module can handle different types of chargers and charging configurations which can be setup in the inputs spreadsheet. For instance, this feature enables the establishment of the state of charge for IPT coupled with overnight plug-in system, or plug-in charger only. As previously described in Section B, (1) provides the consumption between stops from the moment the bus leaves the depot to the moment it returns to it, outside this time frame the bus stays at the depot.

The conceptual model for SoC is based on the assumption that a bus will start its journey from the depot with a full charged battery. From this initial point, $\mathrm{t}_{\text {init }}$, SoC of the bus $k$ can be defined at any time $t$ as illustrated by (2). A singularity appears for $t=0$ at midnight, in this case the anterior instant $t$ 1 corresponds to $t=1439$ meaning 23:59.

$$
\text { SoC }_{k}(t)=\left\{\begin{array}{cl}
C_{\max } & \text { if } \operatorname{SoC}(t-1) \geq C_{\max } \text { oR } t=t_{\text {init }} \\
\text { SoC }_{k}(t-1)-\text { Conso }_{k}(t)+\text { Charge }_{k}(t), & \text { if } \operatorname{SoC}(t-1)<C_{\max }
\end{array}\right.
$$

where: $\mathrm{C}_{\max }$ is maximum capacity of the bus battery = full charge, expressed in $[\mathrm{kWh}], \mathrm{t}_{\mathrm{init}}$, is the moment when the bus leaves the depot , $0 \leq \mathrm{t}_{\text {init }} \leq 1439$ [min], Charge $\mathrm{k}_{\mathrm{k}}(\mathrm{t})$ is the energy charged from the instant $t-1$ to the instant $t$, expressed in $[\mathrm{kWh}]$, Conso $_{\mathrm{k}}(\mathrm{t})$ is the energy consumed from the instant $t-1$ to the instant $t$, expressed in $[\mathrm{kWh}], \mathrm{SoC}_{\mathrm{k}}(\mathrm{t})$ is the $\mathrm{SoC}$ of the bus $k$ at the instant $t$, expressed in [kWh].

\section{Charging load model}

Once the state of charge of each bus has been computed, the Scilab module for charging loads can be launched. All the charger characteristics for each charging locations considered are extracted from the corresponding spreadsheet. Then, a two-step iterative process follows: a list with all the buses stopping at this station is created from the timetables, and for each one of those buses, the corresponding state of charge file is checked for verifying if the bus is effectively charging or not during its opportunity windows. When the bus is effectively charging, the load created is calculated and added to the pre-existing cluster load.

\section{E. Prioritisation of routes electrification}

One of the goals of this project is to provide useful information to stakeholders involved (e.g. DNOs and bus operators $(\mathrm{BO})$ ) to decide which of the bus routes studied within MK are more suitable for their electrification in the short, medium or long term. In other words, establishing a ranking of priorities for the routes analysed, based on the specific characteristics of each of them and the estimated impacts that their electrification would generate. This analysis has been carried out by a MCDA [14]. It was developed following consultations with the project stakeholders. Figure 2 shows the different factors that were taken into account when setting up the MCDA.

Figure 2. MCDA tree for bus routes electrification in Milton Keynes

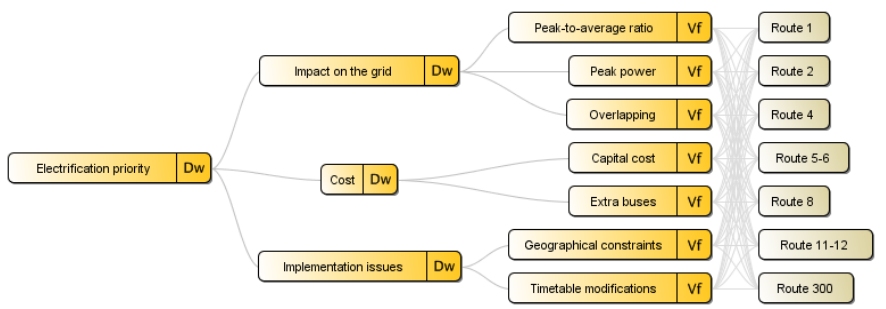

III. RESULTS

\section{A. Single route results}

Starting from route 7 , there has been calculated the energy required, in $\mathrm{kWh}$, for each bus to cover during its daily distance, from leaving the depot in the morning to coming back to the depot in the evening. With 8 buses in route 7 , bus number 5 is the worst case, requiring $383 \mathrm{kWh}$ of electrical energy during a full day. The total energy consumption for the 8 buses in route 7 was estimated to be $2,426 \mathrm{kWh}$, representing an average of $303 \mathrm{kWh}$ per bus. Figure 3 plots the result of the simulation at Wolverton Church Street and Bletchley Bus Station substations. Both IPT chargers, with a $120 \mathrm{~kW}$ power rating are idle overnight, but are used during the day to top up the electric buses batteries. During the active period at Wolverton, there are 52 charging events, whereas for Bletchley, during the active period, there are 26 charging events. Finally, the substation at Arden Park has the series of 8 plug-in chargers of $22 \mathrm{~kW}$ that are used overnight, so they stay idle during the day.

The Scilab model is used to estimate the instant battery SoC level for each bus and each route. The energy level remaining in the battery at any given point, assuming the buses leave the depot in the morning with a full charge. The SoC for bus 5 in route 7 is plotted assuming no delays, some delays, and the bus skipping opportunity recharges; finally, the bus battery state of charge was tested without using any opportunity recharging. The evolution of the state of charge over the day for bus number 5 in these three cases is shown on Figure 4Error! Reference source not found..
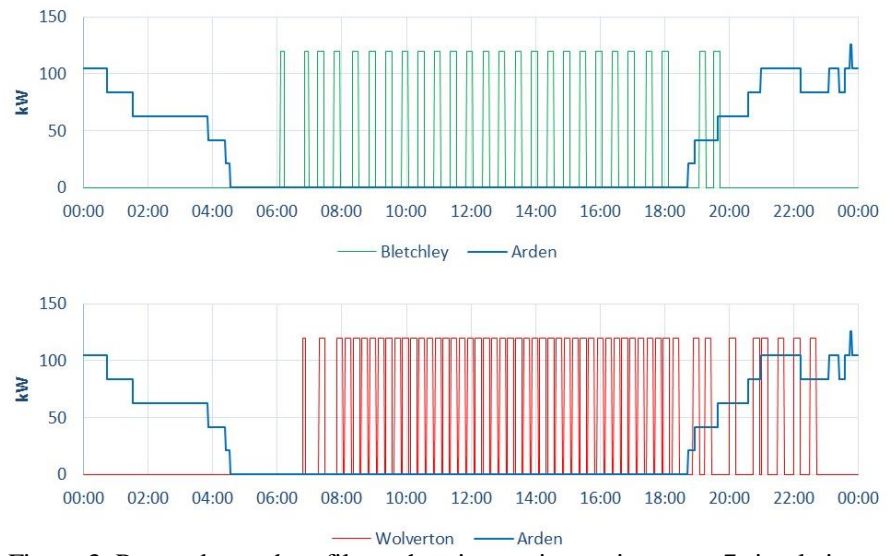

Figure 3. Power demand profile at charging stations using route 7 simulation 


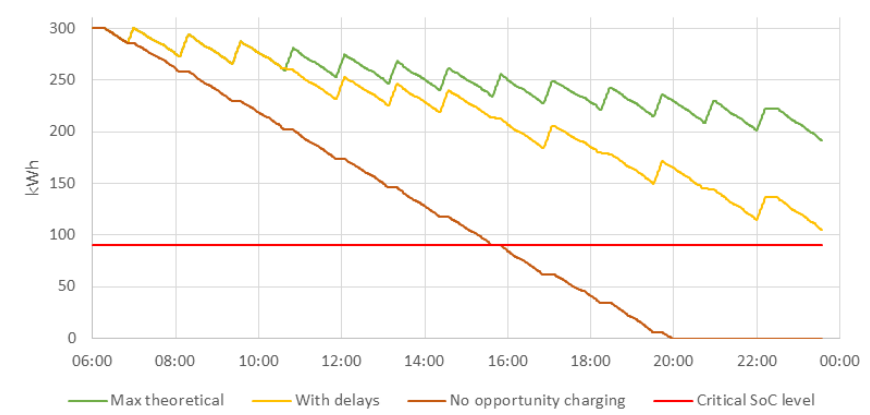

Figure 4. SoC for bus 5 in route 7, comparing performances during a day

\section{B. Electrification routes scenarios}

The routes considered to be electrified have been the most frequent bus routes running within Milton Keynes, which includes routes numbers $1,2,4,5 / 6,7,8,11 / 12$, and 300 . Trying to represent a worst case scenario, the weekday timetables were used for each route, when these buses run typically from early morning to late in the evening, with a frequency of around 15 minutes during the day. It was assumed that the IPT chargers power rating would be $200 \mathrm{~kW}$, higher than the current $120 \mathrm{~kW}$, based on industry projections.

The model was run using the original diesel buses timetables to determine the required energy for a full day operation. The daily energy requirement varies among buses in the same route, based on its characteristics and the total distance travelled. Table 3 shows the estimated average and total energy requirements for every bus route considered.

TABLE III. POWER CONSUMED BY BUS ROUTE

\begin{tabular}{|l|c|c|c|c|c|c|c|c|}
\hline Route & $\mathbf{1}$ & $\mathbf{2}$ & $\mathbf{4}$ & $\mathbf{5 / 6}$ & $\mathbf{7}$ & $\mathbf{8}$ & $\mathbf{1 1 / 1 2}$ & $\mathbf{3 0 0}$ \\
\hline $\begin{array}{l}\text { Average consumption } \\
\text { per Bus [kWh] }\end{array}$ & 397 & 377 & 324 & 324 & 303 & 408 & 185 & 362 \\
\hline $\begin{array}{l}\text { Total consumption } \\
\text { per Route [kWh] }\end{array}$ & 1,984 & 2,636 & 3,886 & 6,483 & 2,426 & 3,261 & 741 & 2,169 \\
\hline
\end{tabular}

\section{Electification prioritasion and $\mathrm{CO}_{2}$ savings}

With the results of the MCDA, two roadmaps were defined to electrify selected bus routes in MK urban area. The scenarios are presented in Table 4, one from the DNO and the other from the $\mathrm{BO}$ perspective, along with potential $\mathrm{CO}_{2}$ savings.

TABLE IV. ELECTRIFICATION PRIOTISATION AND $\mathrm{CO}_{2}$ SAVINGS DEPENDING ON DECISION MAKER, DNO OR BO

\begin{tabular}{|c|c|c|c|c|c|c|}
\hline \multirow{2}{*}{ Year } & \multicolumn{2}{|c|}{ Routes Added } & \multicolumn{2}{c|}{$\begin{array}{c}\text { Total } \\
\text { Electrified [\%] }\end{array}$} & \multicolumn{2}{c|}{$\begin{array}{c}\text { Daily emissions } \\
\text { savings [tC0 }\end{array}$} \\
\hline \multirow{2}{*}{2014} & $D N O$ & $B O$ & $D N O$ & $B O$ & $D N O$ & $B O$ \\
\hline \multirow{2}{*}{2020} & 300 & 7 & $10 \%$ & $10 \%$ & 1.5 & 1.5 \\
\cline { 2 - 7 } & 1 & 2 & $28 \%$ & $30 \%$ & 6.0 & 6.5 \\
\hline \multirow{2}{*}{2030} & $11-12$ & $11-12$ & $31 \%$ & $33 \%$ & 7.6 & 7.2 \\
\cline { 2 - 7 } & 8 & 300 & $45 \%$ & $42 \%$ & 11.1 & 9.5 \\
\hline 2040 & $5-6$ & 4 & $72 \%$ & $59 \%$ & 19.0 & 12.9 \\
\hline \multirow{2}{*}{2050} & 2 & 8 & $84 \%$ & $73 \%$ & 21.9 & 18.9 \\
\cline { 2 - 7 } & 4 & $5-6$ & $100 \%$ & $100 \%$ & 26.2 & 26.2 \\
\hline
\end{tabular}

\section{Clustering of chargers and loads obtained}

The location of the charging stations and their potential clustering has been modelled. In order to scale the route 7 trial up, it was assumed that the charging locations pattern should be replicated in the same way as in route 7 , i.e., two charging points at the start and the end of the route. Table 5 shows the gradual deployment of the IPT chargers and their geographical location in accordance with DNO and BO prioritising pathways until 2050. The DNO prioritisation pathway considered the impacts on the grid factor as very important when setting up the MCDA. Indeed, the likelihood of overlapping and clustering of chargers to occur is delayed until 2040 (with Wolverton Church Street and Water Eaton Buttermere Close having two IPT charging stations). On the other hand, the BO pathway for introduction of IPT chargers does not assign much importance to the impacts on the grid. Therefore, the clustering of chargers starts as early as 2020, and by 2040 there are 4 stations having two IPT chargers. This analysis confirms that the MCDA's ranking and outputs are consistent with the parameters introduced.

TABLE V. ALLOCATION OF IPT CHARGERS IN MK FOR FULL ELECTRIFICATION ACCORDING TO DNO/BO PRIORITISATION

\begin{tabular}{|l|c|c|c|c|c|}
\hline Charging location & $\mathbf{2 0 1 4}$ & $\mathbf{2 0 2 0}$ & $\mathbf{2 0 3 0}$ & $\mathbf{2 0 4 0}$ & $\mathbf{2 0 5 0}$ \\
\hline Bletchley Bus Station & 1 & 1 & 1 & $1 / 2$ & 2 \\
\hline Caldecotte Monellan Grove & & & 1 & 1 & 1 \\
\hline MK Central Railway Station & & $1 / 0$ & 1 & 1 & 1 \\
\hline Kingston District Centre & & & $1 / 0$ & 1 & 1 \\
\hline Magna Park Fen Street & & $1 / 0$ & 1 & 1 & 1 \\
\hline Newport Pagnell Market Hill & & 2 & 2 & 2 & 2 \\
\hline Newton Leys St Helena & & 1 & 1 & 1 & 1 \\
\hline Water Eaton Butter mere Close & & & & $2 / 0$ & 2 \\
\hline Westcroft District Centre & & $0 / 1$ & 1 & $1 / 2$ & 2 \\
\hline Woburn Sands The Swan & & $1 / 0$ & 1 & 1 & 1 \\
\hline Wolverton Church Street & 1 & 1 & 1 & 2 & 3 \\
\hline
\end{tabular}

By running the model for all the bus routes considered to be electrified in the different scenarios, all the loads at the different charging locations have been calculated. The results for the IPT opportunity charging points around the city are shown characterised by the following main indicators: power, daily use, energy consumed, number of charge events, and average frequency of the charges. Table 6 shows these charging characterization at Wolverton Church Street.

TABLE VI. IPT CHARGING CHARACTERISTICS FOR WOLVERTON STREET

\begin{tabular}{|c|c|c|c|c|c|c|c|}
\hline $\begin{array}{c}\text { Charging } \\
\text { location }\end{array}$ & Route & $\begin{array}{c}\text { Year of } \\
\text { introduction } \\
\text { priority } \\
\text { DNO/BO }\end{array}$ & $\begin{array}{c}\text { Energy } \\
\text { consumed } \\
{[\mathbf{k W h}]}\end{array}$ & $\begin{array}{c}\text { Usage } \\
\text { per } \\
\text { day } \\
{[\%]}\end{array}$ & $\begin{array}{c}\text { Usage } \\
\text { active } \\
\text { period } \\
{[\%]}\end{array}$ & $\begin{array}{c}\text { Charge } \\
\text { events } \\
{[\text { [No.] }}\end{array}$ \\
\hline \multirow{2}{*}{$\begin{array}{c}\text { Wolverton } \\
\text { Church } \\
\text { Street }\end{array}$} & 7 & 2014 & 2014 & 1230 & 43 & 65 & 52 \\
\cline { 2 - 8 } & $5 / 6$ & 2040 & 2050 & 2270 & 47 & 65 & 94 \\
\hline
\end{tabular}




\section{E. IPT vs PLUG-IN only technology}

Using the original timetables of the bus routes and removing all the opportunity charging events, a plug-in-only scenario has been created, where the charging occurs only overnight at the depot at Arden Park. Table 5 shows the evolution of the loads along the different electrification scenario for both DNO and BO priorities. In the DNO priority pathway the peak power generated is generally lower for the same $\mathrm{BO}$ electrification scenario.

TABLE VII. PLUG-IN OVERNIGHT CHARGING AT THE DEPOT FOR FUTURE SCENARIOS AND BOTH PRIORITIES PATHWAYS, DNO/BO

\begin{tabular}{|c|c|c|c|c|}
\hline $\begin{array}{c}\text { Electrification } \\
\text { scenario }\end{array}$ & $\begin{array}{c}\mathbf{N}^{\mathbf{0}} \text { c } \\
\text { chargers }\end{array}$ & $\begin{array}{c}\text { Power per } \\
\text { charger } \\
{[\mathbf{k W}]}\end{array}$ & $\begin{array}{c}\text { Peak } \\
\text { power } \\
{[\mathbf{k W}]}\end{array}$ & $\begin{array}{c}\text { Daily } \\
\text { Energy } \\
\text { consumption } \\
{[\mathbf{k W h}]}\end{array}$ \\
\hline $\mathbf{2 0 1 4}$ & 8 & 22 & 132 & 776 \\
\hline $\mathbf{2 0 2 0}$ & $19 / 20$ & 22 & $264 / 308$ & $1651 / 2124$ \\
\hline $\mathbf{2 0 3 0}$ & $31 / 30$ & 22 & $396 / 374$ & $2689 / 2558$ \\
\hline $\mathbf{2 0 4 0}$ & $53 / 50$ & 22 & $550 / 638$ & $3603 / 4505$ \\
\hline $\mathbf{2 0 5 0}$ & 72 & 22 & 770 & 5419 \\
\hline
\end{tabular}

The simulation gives expected results, with the IPT load distributed across the city, whereas the demand is concentrated at Arden Park for the plug-in only. This is reflected in Figure 4, as higher peak demand is required at Arden Park, increasing in a sharper way than the IPT case and a peak level between 3 and 4.5 times higher than when using IPT opportunity chargers. Figure 5 shows a comparison between city-wide demands for both technologies, considering Milton Keynes as a whole cluster. The comparison indicates a very different nature of load profiles produced by both technologies. The plug-in one stays idle during the most part of the operational day whereas a baseload is created for its counterpart. As detailed in the section F, the IPT profile is comparable to a typical load for industrial and commercial appliances, making no real difference for balancing a typical city load but just adding itself to the current existing profile.

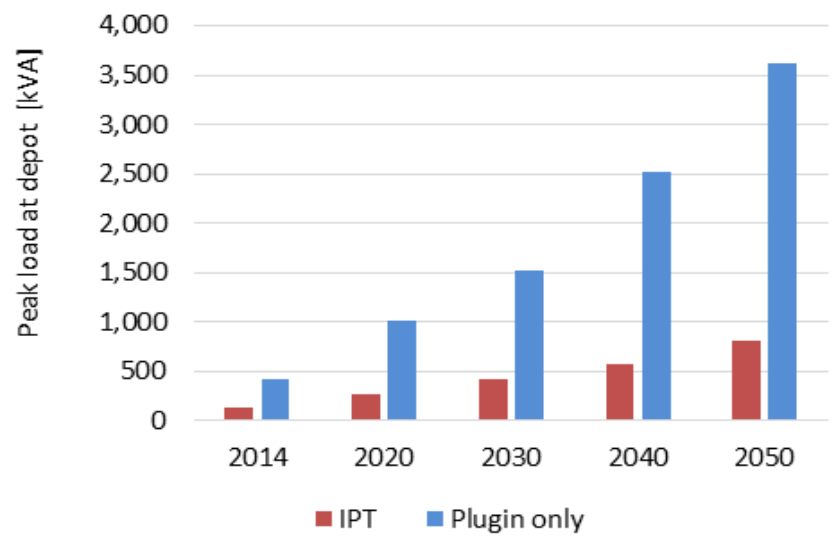

Figure 4. Daily peak load at depot per year simulated

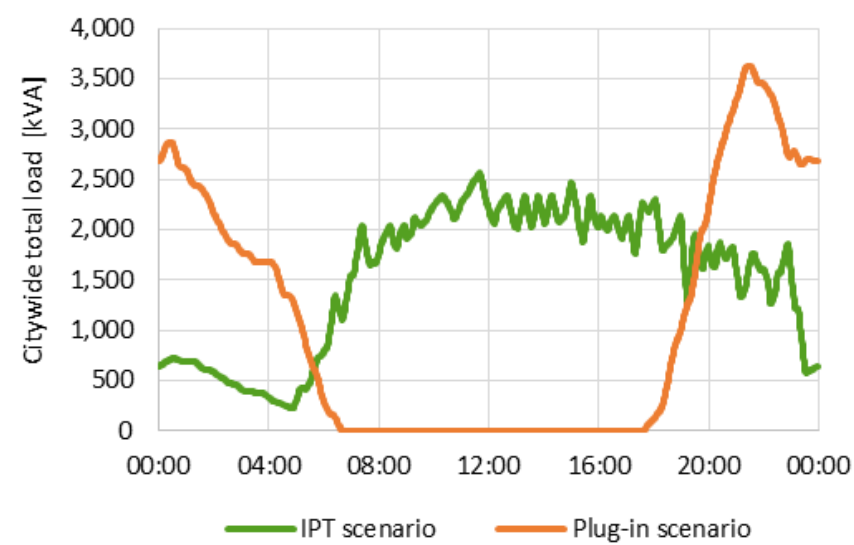

Figure 5. Load profiles in MK comparing IPT vs Plug-in only scenarios

F. Comparison to I\&C demand profiles

The demand from IPT chargers has been compared to representative I\&C load profiles obtained from the WPD FALCON energy model for MK [18].

The comparison matches the modelled instant power demand on the charging stations and the 30 minutes average power demand on I\&C buildings. It is assumed that the load factor of the industrial and commercial buildings in each 30minute is close to $100 \%$, so the stations peak power demand and the 30-minute average power demand from I\&C are comparable. In the case of stations with one IPT charger, two stations were selected for the comparison: Bletchley 2014 and Kingston 2040, Figure 6. These charging stations represent the cases with the lowest and highest daily energy consumed, respectively. The difference in energy consumption is due to the frequency of buses, the duration of the active period, and the IPC charger power. Bletchley is part of the route 7 trial, using a $120 \mathrm{~kW}$ charger, whilst Kingston uses a $200 \mathrm{~kW}$ charger. Figure 7 displays the comparison between IPT charging stations with more than one charger and I\&C profiles. The peak power demand from charging station with 1 charger $i$ comparable to the power demand from 2 or 3 Tesco Metro-sized stores. Stations with 2 chargers have a peak power as high as the combination of the demand from one Shopping Park, one restaurant and two gymnasiums. Finally, the station with 3 chargers has a peak power demand comparable to the sum of one Shopping Park and three

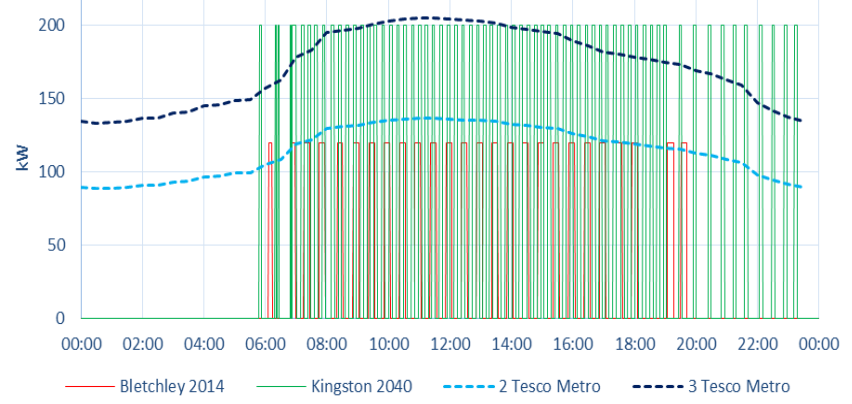

restaurants.

Figure 6. Comparison of two IPT stations with one IPT charger with two I\&C load demand profiles 


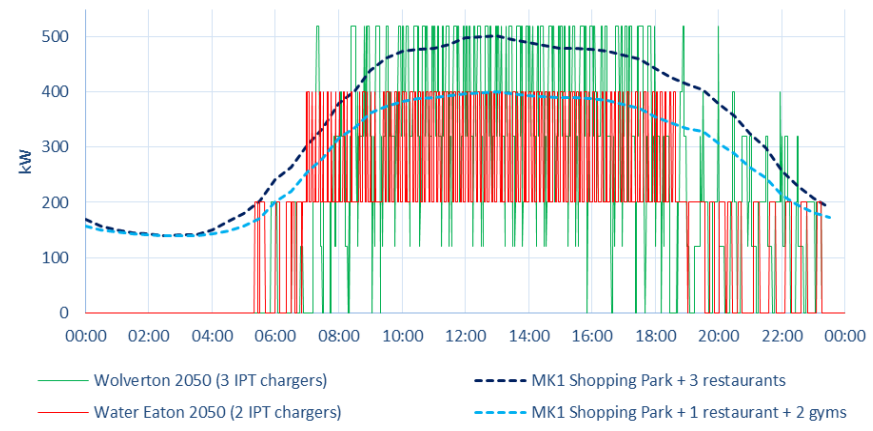

Figure 7. Comparison of two IPT stations with two and three IPT chargers with two I\&C load demand profiles

\section{CONCLUSIONS}

The current trial of the Inductive Power Transfer (IPT) technology can be extrapolated to the most demanding urban routes within Milton Keynes.

For this study, a complete model has been created for simulating the use of the IPT technology in all MK urban routes, based on the characteristics and actual power requirements of the current trial. This has allowed to evaluate the potential effects that the adoption of IPT charging for different future scenarios of electrification would have; in terms of energy requirements, $\mathrm{CO}_{2}$ emission savings and impacts on the electricity network.

The model has also simulated the performance of all these routes under a different battery size and charging arrangement, i.e., buses with a battery capacity enough to cover their whole daily journey without intermediate opportunity charges, by charging only overnight.

The electric buses deployment introduces new significant loads to the electricity distribution network. The key findings regarding these new loads under different future scenarios considered can be summarised as follows:

* The peak loads at the IPT charging locations can be introduced gradually, by postponing the generation of clusters (two or more routes charging at the same location), provided that the impacts on the electricity network are regarded as important in the prioritisation of the new routes to electrify.

* The comparison between the IPT system and the overnight-plugin-only system shows that significantly different load profiles in terms of location and time are produced. On the other hand, the peak load at the depot could be up to 4 times higher with the plugin system, as the complete charge of the buses is concentrated in a single location, but it would be generated during night, avoiding overlapping with other daytime peak load.

The potential savings in carbon emissions reflects that an electrification of urban buses in Milton Keynes will be significant. The level of daily carbon savings would be equivalent to the emissions of about 1,600 cars driving a distance of $100 \mathrm{~km}$, and would prevent releasing to the atmosphere near 9,500 tons of $\mathrm{CO}_{2}$ per year. Furthermore, the results attest that the electrification of all the urban highfrequency bus routes should be possible in a similar way to the current route 7 trial, saving up to 26 tons of $\mathrm{CO}_{2}$ daily with a complete electrification by 2050 . It would create high peak loads at the inductive charging locations shared between several routes, which would be comparable to other typical industrial and commercial loads but much more intermittent in nature.

\section{REFERENCES}

[1] Milton Keynes Council - Sustainability Team (2014) Imagine MK 2050 Strategy. Available: http://www.milton-keynes.gov.uk/environmentalhealth-and-trading-standards/mk-low-carbon-living/imagine-mk-2050project (Accessed: 6 April 2015).

[2] Miles, J. and Potter, S. (2014) 'Developing a viable electric bus service: The Milton Keynes demonstration project.' Research in Transportation Economics, 48 Elsevier Ltd, pp. 357-363.

[3] Milton Keynes Council (2013) The Milton Keynes Electric Bus Project. Available: http://www.milton-keynes.gov.uk/streets-transport-and-20 parking/bus-travel/bus-projects/electric-bus (Accessed: 6 April 2015).

[4] Lajunen, A. (2014) 'Energy consumption and cost-benefit analysis of hybrid and electric city buses', Transportation Research Part C: Emerging Technologies, 38 Elsevier Ltd, pp. 1-15.

[5] Pihlatie, M., Kukkonen, S., Halmeaho, T., Karvonen, V. and Nylund, N. (2014) 'Fully Electric City Buses - The Viable Option'. Available: http://www.vtt.fi/inf/julkaisut/muut/2014/OA-Fully-Electric.pdf (Accessed: 10 March 2015).

[6] Mwasilu, F., Justo, J.J., Kim, E.K., Do, T.D. and Jung, J.W. 'Electric vehicles and smart grid interaction: A review on vehicle to grid and renewable energy sources integration', Renewable and Sustainable Energy Reviews, 34 Elsevier, pp. 501-516.

[7] IPT Technology GmbH (2014) References. Available: http://www.ipttechnology.com/images/files/REF9000-0001-EN_IPT_Technology GmbH.pdf (Accessed: 23 March 2015)

[8] Talbot, J. (2014) Milton Keynes Electric Bus Demonstration Project. Available: http://www.testsitesweden.com/sites/default/files/content/ PDF/electrified_public_transport_may_22_talbot_-_0687_efis__presentation_template_may_2014.pdf (Accessed: 3 March 2015).

[9] Morais, H., Sousa, T., Vale, Z. and Faria, P. (2014) 'Evaluation of the electric vehicle impact in the power demand curve in a smart grid environment', Energy Conversion and Management, 82 Elsevier Ltd, pp. 268-282.

[10] Dharmakeerthi, C., Mithulananthan, N. and Saha, T.K. (2011) 'Overview of the Impacts of Plug-in minor partein Electric Vehicles on the Power Grid', Innovative Smart Grid Technologies Asia (ISGT), 2011 IEEE PES, pp. 1-8.

[11] UK Power Networks (2014) Impact \& opportunities for wide-scale EV deployment. Available: http://innovation.ukpowernetworks.co.uk/ innovation/en/Projects/tier-2-projects/Low-Carbon-London-(LCL) (Accessed: 6 March 2015)..

[12] Dharmakeerthi, C., Mithulananthan, N. and Saha, T.K. (2011) 'Overview of the Impacts of Plug-in minor partein Electric Vehicles on the Power Grid', Innovative Smart Grid Technologies Asia (ISGT), 2011 IEEE PES, pp. 1-8.

[13] Kippar, J. (1997) 'Model development life cycle', [Lecture], (Institute of Informatics, Tallinn University) Available: http://minitorn.tlu.ee/ jaagup/uk/ds/chp2/CHAP2 1.HTM. (Accessed: 11 April 2015).

[14] Løken, E. (2007) 'Use of multicriteria decision analysis methods for energy planning problems', Renewable and Sustainable Energy Reviews, 11(7), pp. 1584-1595.

[15] Scilab (2015), Available: http://www.scilab.org/

[16] Lajunen, A. (2013) 'Energy-optimal velocity profiles for electric city buses', IEEE International Conference on Automation Science and Engineering, pp. 886-891.

[17] Pihlatie, M., Kukkonen, S., Halmeaho, T., Karvonen, V. and Nylund, N. (2014) 'Fully Electric City Buses - The Viable Option'. Available: http://www.vtt.fi/inf/julkaisut/muut/2014/OA-Fully-Electric.pdf (Accessed: 3 March 2015).

[18] Western Power Distribution Innovation (2015) Project FALCON, Load estimation. Available: http://www.westernpowerinnovation.co.uk/ Document-library/2015/Project-FALCON-Load-Estimation.aspx (Accessed: 23 September 2015) 